\title{
Argininosuccinic Aciduria in Monilethrix
}

\begin{tabular}{|l|l|l|}
\hline J.C.M. & & Grosfeld \\
\hline J. & & Mighorst \\
\hline T. & & Moolhuysen \\
\hline
\end{tabular}

Bergen op Zoom

Authors' address: Dr. J. C M. Grosfeld, Stationsstraat 22, Bergen op Zoom (Netherlands)

In two young unrelated patients with Monilethrix argininosuccinic acid in different urine samples could be demonstrated. This abnormal amino acid was not constantly present and showed otherwise varying degrees of intensity. Monilethrix seems to be an "inborn error of metabolism" as could be stated for Trichorrhexis Nodosa. Published in the Lancet 10-10: 789-791 (1964).

) 